Pasado y Memoria

ISSN: 2386-4745

Núm. 23, 2021, pp. 407-431

https://doi.org/10.14198/PASADO2021.23.17

Estudios

\title{
Entre la biografía y el mito: la representación audiovisual de Winston Churchill
}

\author{
From biography to myth: the audiovisual \\ representation of Winston Churchill
}

\author{
José-Vidal Pelaz López \\ Universidad de Valladolid, España \\ pelaz@fyl.uva.es \\ http://orcid.org/0000-0001-7255-4430
}

Recibido: 19/01/2021

Aceptado: 24/05/2021

Cómo citar este artículo: PELAZ LÓPEZ, José-Vidal (2021). Entre la biografía y el mito: la representación audiovisual de Winston Churchill. Pasado y Memoria. Revista de Historia Contemporánea, (23), pp. 407-431, https://doi.org/1014198/ PASADO2021.23.17

\section{Resumen}

Winston Churchill fue sin duda uno de los líderes más carismáticos del siglo XX. Lo fue en vida, y su mito se consagró tras su muerte. El presente trabajo estudia el tratamiento audiovisual de este personaje en el cine y la televisión hasta nuestros días. Se pretende identificar los rasgos del mito de Churchill, tal y como los medios los han venido transmitiendo a la sociedad en las últimas décadas, para contrastar la imagen resultante con el Churchill histórico. El objetivo final es intentar calibrar hasta que punto los medios audiovisuales, en su condición de transmisores del conocimiento histórico, están reinterpretando o no al personaje, al margen de las biografías convencionales publicadas.

Palabras clave: Winston Churchill; Biografía; Cine; Televisión.

\section{Abstract}

Winston Churchill was undoubtedly one of the most charismatic leaders of the 20th century, both during his life and after his death, when the myth was consecrated. This

C2021 José-Vidal Pelaz López 
paper studies the audiovisual treatment of the character both in film and television to date. The aim is to identify the features of Churchill's myth, as transmitted to society by the media, over the last decades and then compare said image with historic Churchill. The ultimate goal is to try to determine to what extent the audiovisual media -as transmitters of historical knowledge- are reinterpreting the character regardless of conventional, published biographies.

Keywords: Winston Churchill; Biography; Movies; Television.

\section{Imágenes y palabras en la construcción de un mito}

Todo hombre público representa en cierto sentido un papel, pero Winston Churchill parece haber sido especialmente consciente de ello, creando un personaje que ha sobrevivido a su muerte. Según David Lloyd George, Churchill era «igual que un actor: le gustan las luces de candilejas» (Hayward, 2008: 20-21). El punto culminante de esa vocación por la escena habría sido el verano de 1940 cuando se convirtió en «un Douglas Fairbanks de la política» (Wenden, 1993: 226). Como apunta Bédarida (siguiendo a Max Weber) fue entonces cuando se consolidó su liderazgo carismático, forjado en un momento de crisis (la amenaza de invasión), ritualizado mediante señales visibles (discursos, gestos, indumentaria) y que perdura en el tiempo (la nación no olvida al héroe que la salvó en el instante más oscuro) (2002: 389-393). Había nacido un «niño mimado de la mitología de nuestro tiempo»:

«Artista en materia de retórica, actor que supo siempre calcular bien sus efectos, Churchill, ayudado por la fotografía, el cine, los medios de comunicación -sin olvidar la pintura-se benefició ad libitum de imágenes legendarias inscritas hasta en el inconsciente. Tan solo citar su nombre, ya surge la figura del hombre con el habano en la boca y los dedos abiertos en la $\mathrm{V}$ de la victoria, ataviado con vestimentas pintorescas, representando la prestancia y la cólera, adversario implacable de Hitler y defensor de la libertad del mundo» (Bédarida, 2002: 23)

Casi todas la biografías de Churchill hacen referencia a su utilización de los medios para la edificación del mito en vida, como hemos visto en Bédarida y también subrayan Brendon (1994), Roberts (2003; 2019) o Hastings (2010). Pero no estaríamos en situación de comprender el alcance histórico de su figura sin tener en cuenta el papel que han desempeñado también el cine y la televisión a la hora de moldear su imagen tras su muerte. Resulta por eso sorprendente la escasez de autores que han abordado este tema. Tan solo Wenden (1993) se ocupa de ello y más recientemente algunos artículos de Hayward 
(2017), Roberts (2018), Frago y Sierra (2020) o el monográfico de la revista Finest hour, editada por la Churchill Society en 2018.

Este trabajo persigue dos objetivos esenciales: caracterizar los rasgos del mito churchilliano tal y cómo los transmiten los medios audiovisuales y contrastar esa imagen con el Churchill de los libros de historia. Seguimos los clásicos estudios de Marc Ferro (1995; 2008) sobre la virtualidad del cine como fuente y agente para la historia, o los de Pierre Sorlin $(1980 ; 1996)$ en relación al cine como expresión ideológica, y los de Santiago de Pablo (2001) o Shlomo Sand (2004) sobre cómo las películas cuentan la historia. También se han tenido en cuenta las reglas del biopic a través de los trabajos de Ángel Luis Hueso (2001), Gloria Camarero (2011), o Brown y Vidal (2014), contrastándolas con el genero biográfico en la historiografía tal como lo abordan José Luis Gómez Navarro (2005), François Dosse (2007) o Isabel Burdiel (2014). Pero sobre todo nos apoyamos en Robert Rosenstone $(1997 ; 2014)$ o Julio Montero (2001) en el sentido de considerar el audiovisual como un nuevo tipo de relato histórico, diferente de la historia escrita. Sin querer entrar en los planteamientos de Hayden White acerca de la relación entre los acontecimientos y el discurso (Erice, 2020), en el caso del audiovisual (y particularmente del biopic) su carácter de representación artística del pasado, y por tanto la apelación a la emoción por encima de la razón, lo diferencian de la historia convencional: «Si el biofilm no puede lograr nunca la riqueza en los detalles o la profundidad de análisis de una extensa biografía escrita, sí que puede (...) darnos un pedazo de una vida, intensificado por el género del drama y el poder del medio» (Rosenstone, 2014:189). Estas cualidades intrínsecas del audiovisual hacen desconfiar de él al historiador profesional (Montero, 2001) -si bien ya Dosse ponía de relieve que la biografía mostraba la tensión existente en la historia «entre su polo científico y su polo de ficción» (2007: 24)- pero a la vez contribuyen a la divulgación social masiva del pasado dejando claro que la historia se puede construir, como dice De Groot, de múltiples maneras (películas, series, museos, videojuegos, Internet) saliendo de las Facultades de Historia y entrando en el terreno del mito y de la cultura popular (2016a: 2 y 311$)$.

Para esta investigación se han seleccionado aquellos largometrajes y series de televisión «de intencionalidad histórica» (Rosenstone, 2014: 9) en los que aparece Winston Churchill como personaje. En el cuadro adjunto pueden verse divididos en dos grupos. El primero (en sombreado) incluye las producciones netamente biográficas, es decir las que se ocupan de forma monográfica de algún episodio de su vida. En ellas descansará el peso del análisis, dedicando atención preferente a El instante más oscuro (Joe Wright, 2017) por ser el título 
en el que se puede observar con más claridad el proceso de mitificación de que viene siendo objeto la figura de Churchill en la actualidad. En un segundo plano situamos el resto de productos audiovisuales en los que el personaje aparece de manera secundaria.

Sobre este abundante material se reconstruirá la «película» de la vida de Churchill, valorando la desigualdad de tratamiento que ha merecido cada una de sus etapas, los principales enfoques que sobre el personaje se han sucedido, los contextos históricos en los que las películas o series se han producido (y de que forma han determinado las distintas interpretaciones), o las carencias $\mathrm{u}$ ocultaciones. Como plantea Rosenstone en su ensayo sobre la figura de John Reed (2014: 173-192), nos centraremos en el análisis del discurso audiovisual, tanto explícito como subyacente, estableciendo un diálogo crítico con el discurso historiográfico establecido, comparando unas visiones con otras, e incluso con los testimonios escritos del propio protagonista. Por eso no haremos distinción entre formatos, siendo conscientes de sus diferencias (Rueda et al., 2009). Quedan intencionadamente fuera del estudio las «recreaciones con fines documentales» y los documentales en sentido estricto, a pesar de ser muy numerosos. En ambos casos por considerar que pertenecen más a un género «didáctico» dentro del audiovisual, más que al de «entretenimiento», que es en el que se concentra el mayor interés del público no especializado (Hernández, 2004).

En definitiva, lo que se pretende es poner en relación el Churchill de los libros de Historia con el Churchill audiovisual para determinar hasta qué punto y de qué manera el mito churchilliano, construido ya por él mismo en vida, mantenido luego por los historiadores, ha encontrado una nueva forma de perpetuación y renovación a través de las pantallas.

\section{Cuadro 1: Presencia de Winston Churchill en el cine y la televisión}

\begin{tabular}{|c|c|c|}
\hline \multirow{2}{*}{$\begin{array}{l}\text { Época } \\
\text { victoriana } \\
\text { (1874-1901) }\end{array}$} & El joven Winston (Richard Attemborough, 1972) & Film \\
\hline & Jennie: Lady Randolph Churchill (James Cellan Jones, 1974) & Serie TV \\
\hline \multirow{6}{*}{$\begin{array}{l}\text { Etapa } \\
\text { eduardiana } \\
(1901-1914)\end{array}$} & The life and Times of David Lloyd George (John Hefin, 1981) & Serie TV \\
\hline & Las Aventuras del joven Indiana Jones (George Lucas, 1992) & Serie TV \\
\hline & Titanic: sangre y acero (Ciaran Donnelly, 2012) & Serie TV \\
\hline & 37 días (Justin Hardy, 2014) & Serie TV \\
\hline & Sufragistas (Sarah Gavron, 2015) & Film \\
\hline & Entre la razón y la locura (Farhad Safinia, 2019) & Film \\
\hline
\end{tabular}




\begin{tabular}{|c|c|c|}
\hline $\begin{array}{l}\text { Gran Guerra } \\
(1914-1918)\end{array}$ & Deadline Gallipoli (Michael Rymer, 2015) & Serie TV \\
\hline \multirow{5}{*}{$\begin{array}{l}\text { Posguerra } \\
1918-1929\end{array}$} & Days of Hope (Ken Loach, 1975) & Serie TV \\
\hline & $\begin{array}{l}\text { The Gathering Storm (Andrew Osborne y Herbert Wise) } \\
\text { (1974) }\end{array}$ & Telefilm \\
\hline & The Treaty (Jonathan Lewis, 1991) & Telefilm \\
\hline & Kurtulus (Ziya Öztan, 1994) & Serie TV \\
\hline & La reina del desierto (Werner Herzog, 2015) & Film \\
\hline \multirow{8}{*}{$\begin{array}{l}\text { Preguerra } \\
1929-1939\end{array}$} & Eduardo y la Sra Simpson (Waris Hussein, 1978) & Serie TV \\
\hline & $\begin{array}{l}\text { Winston Churchill: The Wilderness Years (1929-1939) } \\
\text { (Ferdinand Fairfax, 1981) }\end{array}$ & Serie TV \\
\hline & The woman he loved (Charles Jarrott, 1988) & Telefilm \\
\hline & Bertie and Elizabeth (Giles Foster, 2002) & Telefilm \\
\hline & Amenaza de tormenta (Richard Loncraine, 2002) & Telefilm \\
\hline & Wallis E Edward (David Moore, 2005) & Telefilm \\
\hline & El discurso del rey (Tom Hooper, 2010) & Film \\
\hline & Peaky Blinders (Stephen Knight, 2013-2019) & Serie TV \\
\hline \multirow{19}{*}{$\begin{array}{l}\text { Segunda } \\
\text { Guerra ) } \\
\text { Mundial } \\
\text { (1939-1945) }\end{array}$} & Misión en Moscú (Michael Curtiz, 1943) & Film \\
\hline & Operación Crossbow (Michael Anderson, 1965) & Film \\
\hline & Peenemünde (Falk Harnack, 1970) & Telefilm \\
\hline & Ha llegado el águila, (John Sturges, 1970) & Film \\
\hline & La Batalla de Berlín (Yury Ozerov, 1971) & Film \\
\hline & Ike (Boris Sagal, 1979) & Serie TV \\
\hline & Mers El-Kebir (Pierre Cardinal, 1979) & Telefilm \\
\hline & FDR: The last year (Anthony Page, 1980) & Telefilm \\
\hline & Churchill and the generals (Alan Gibson 1981) & Telefilm \\
\hline & Vientos de guerra (Dan Curtis, 1983) & Serie TV \\
\hline & Yalta (Yves-André Hubert, 1984) & Telefilm \\
\hline & El ultimo bastión (George Miller y Chris Thompson, 1984) & Serie TV \\
\hline & Casablanca express (Sergio Martino, 1988) & Film \\
\hline & Recuerdos de guerra (Dan Curtis, 1989 & Serie TV \\
\hline & Bomber Harris (Michael Darlow, 1989) & Telefilm \\
\hline & Moi, général de Gaulle (Denys Granier-Deferre, 1990) & Telefilm \\
\hline & Dieppe (John N. Smith, 1993) & Serie TV \\
\hline & Cuando los leones rugieron (Joseph Sargent, 1994) & Serie TV \\
\hline & Churchill: The Hollywood years (Peter Richardson, 2004) & Film \\
\hline
\end{tabular}




\begin{tabular}{|c|c|c|}
\hline \multirow{10}{*}{$\begin{array}{l}\text { Segunda } \\
\text { Guerra ) } \\
\text { Mundial } \\
\text { (1939-1945) }\end{array}$} & Ike: desembarco en Normandía (Robert Harmon, 2004) & Telefilm \\
\hline & Le grand Charles (Bernard Stora, 2006) & Serie TV \\
\hline & En la tormenta (Thadeus O'Sullivan, 2009) & Telefilm \\
\hline & Jackboots on Whitehall (Rory y Edward McHenry, 2010) & Film \\
\hline & FDR: American Badass! (Garrett Brawith, 2012) & Film \\
\hline & Churchill (Jonathan Teplitzky, 2017 & Film \\
\hline & El instante más oscuro (Joe Wright, 2017) & Film \\
\hline & Cicerón (Serdar Akar, 2019) & Serie TV \\
\hline & De Gaulle (Gabriel Le Bomin, 2020) & Film \\
\hline & El buen traidor (Christina Rosendhal, 2020) & Film \\
\hline \multirow{8}{*}{$\begin{array}{l}\text { Últimos años } \\
(1945-1965)\end{array}$} & Suez, 1956 (Michael Darlow, 1979) & Serie TV \\
\hline & Lord Mountbatten: The last viceroy (Tom Clegg, 1986) & Serie TV \\
\hline & Onassis: el hombre más rico del mundo (Waris Hussein, 1988) & Serie TV \\
\hline & Callas y Onassis (Giorgio Capitani, 2005) & Serie TV \\
\hline & $\begin{array}{l}\text { The Crown (Peter Morgan, 2016) temporada } 1 \text {, episodios } 1 \text {, } \\
4,7,8 \text { y sobre todo } 9 \text { ) }\end{array}$ & Serie TV \\
\hline & El secreto de Churchill (Charles Sturridge, 2016) & Telefilm \\
\hline & Cerca de tu enemigo (Stephen Poliatoff, 2016) & Serie TV \\
\hline & El último virrey de la India (Gurinder Chadha, 2017) & Film \\
\hline
\end{tabular}

Fuente: Elaboración propia.

\section{Churchill y los medios}

Churchill cultivó siempre con esmero su relación con los medios de comunicación, no en vano edificó su carrera política sobre la popularidad que le proporcionó su condición de reportero de guerra en Cuba, India, Sudán o Sudáfrica. A lo largo de su vida fue colaborador habitual de la prensa, tuvo entre sus amigos a destacados magnates como Beaverbrook o Hearst y utilizó con maestría la radio durante la Segunda Guerra Mundial. Tenía 21 años cuando los hermanos Lumière hicieron su primera proyección pública del cinematógrafo y, hasta tal punto comprendió el valor del nuevo invento, que estuvo cerca de llevarse consigo una cámara a la guerra de los bóer, pero desistió cuando supo que la empresa de Edison se le había adelantado (Gilbert, 2006: 28). Posó con asiduidad para los noticiarios (cada semana durante la guerra, recuerda Bédarida, entre 25 y 30 millones de personas veían su rostro en los cines) y cultivó la amistad de poderosos hombres de la industria como Alexander Korda (Wenden, 1993: 231 y ss). Hasta finales de los años veinte Churchill 
consideraba el cinematógrafo como un entretenimiento de la clase obrera. Esa actitud empezó a cambiar con la llegada del sonoro (Wenden, 1993: 227). Fishman (1964), Pearson (1993), Jenkins (2002), Hayward (2008) o Gilbert (1988 y 2006) nos dan cuenta de su afición hacia las películas de acción, los westerns, las bélicas y las de trama política y de su relación con actores y productores. Es conocido su affaire con Ethel Barrymore (Fishman, 1964: 23-24) y su famoso viaje a Hollywood en 1929, donde fue agasajado por William Randolph Hearst, y del que quedó constancia filmada (Nasaw, 2005: 501-503). En los años treinta probó a escribir un guion sobre la vida de Jorge $\mathrm{V}$, que no se rodó, y fue asesor del proyecto que acabaría siendo Lawrence de Arabia, de David Lean (Hayward, 2008: 21). Su secretario político cuenta cómo le entusiasmó Lo que el viento se llevó o le aburrió Ciudadano Kane (Colville, 2007: $358,440)$. El propio Churchill dejó referencias al séptimo arte en Pensamientos $y$ aventuras $^{1}$ (1943) o en Mi juventud (2010). Hasta su hija Sarah haría sus pinitos en el cine junto a Fred Astaire y Ginger Rogers en Bodas reales (Stanley Donen, 1951).

Churchill captó pronto las posibilidades propagandísticas de la gran pantalla. Le entusiasmaban los noticiarios de March on time, pero también comprendió que las películas de ficción actuaban sobre la parte emocional de los individuos. Durante la guerra, su admiración por dos cintas de tema claramente patriótico como Lady Hamilton (Alexander Korda, 1941) (se dice que la vio hasta diecisiete veces) y Enrique V (Lawrence Olivier, 1944), nos lleva a pensar que Churchill trazaba un paralelismo entre sus heroicos protagonistas y su propio papel en la Inglaterra del blitz (Hastings, 210: 622), y que esperaba que el público en las salas hiciese lo mismo. Por la razón opuesta intentó impedir que se rodase Vida y muerte del coronel Blimp (Michael Powell y Emeric Pressburguer, 1943), aduciendo que iría «en detrimento de la moral del Ejército» (Brendon, 1994: 194,195; Wenden, 1993: 234)².

Hasta su muerte Churchill continuó siendo aficionado al cine. Entre las producciones que visionó en sus últimos años estaban varias que reconstruían aspectos de su propia vida como Tempestad sobre el Nilo (Zoltan Korda, 1955), que recogía la batalla de Omdurmán en la que había participado en sus tiempos mozos, o El puente sobre el río Kwai (David Lean, 1957) y sobre todo, Hundid el Bismarck (Lewis Gilbert, 1960). Según un testigo presencial, con casi noventa años, Winston parecía revivir recordando aquellos históricos momentos (Gilbert, 1988: 1255, 1336).

1. Concretamente en su artículo «Efectos de las masas en la vida moderna», pp. 252-265

2. Una vez producida la película fue acortada varias veces. Hubo que esperar a finales de los años setenta para verla en su integridad (Pilard, 1998: 34) 
La relación de Churchill con respecto a la televisión no fue tan estimulante. Si el cine llegó en su etapa de juventud, la televisión lo haría en la vejez. En 1932 afirmaba que antes de cincuenta años «Telefonía sin hilos y televisión (...) permitirían a sus poseedores conectar con cualquier local dotado de instalación análoga y oír y tomar parte en las conversaciones de igual modo que si echasen la cabeza por la ventana» (Churchill, 1943: 267-280). Tras la guerra, la pequeña pantalla se convirtió en una realidad a la que costaba acostumbrarse:

«ahora uno tiene que pensar cada palabra que dice, porque todo el tiempo la gente le está escuchando en el país entero. Sería una cosa intolerable que, encima, uno tuviera que preocuparse por su aspecto físico, porque el país entero está mirando» (Moran, 1967: 772).

Que la televisión había llegado demasiado tarde para Churchill quedó de manifiesto con ocasión de su dimisión en 1955. Para ese día estaba anunciada una huelga de prensa, y al partido conservador se le ocurrió que grabase un mensaje de despedida en la BBC. El programa de tres minutos de duración se rodó, pero nunca fue emitido por decisión expresa del propio Churchill. El avejentado aspecto del viejo león no era precisamente muy telegénico (Gilbert, 1988: 1119). No obstante, la pequeña pantalla también haría su aportación a la construcción del mito emitiendo en directo su funeral en 1965: «Se ha calculado que la mitad de la población británica siguió a través de las pantallas la transmisión de la ceremonia, además de la décima parte de la población mundial: cifras fantásticas para la época» (Bédarida, 2002: 14).

Mientras Churchill vivió hubo un cierto pudor por encarnar su figura en el cine o la televisión. En 1935 era interpretado por un actor por primera vez en la película Royal Cavalcade ${ }^{3}$. También aparece en Misión en Moscú (Michael Curtiz, 1943), pero lo más habitual fue que un actor imitara su voz. Así ocurría en Capitanes de las nubes (Michael Curtiz, 1942), Rommel el zorro del desierto (Henry Hathaway, 1951), Operación Tirpitz (Ralph Thomas, 1955) o El hombre que nunca existió (Ronald Neame, 1956). En la primera gran serie documental biográfica titulada Winston Churchill: los años valerosos (Anthony Bushell y John Schlesinger, 1960), Richard Burton ponía voz al héroe todavía vivo. En el mismo año de su muerte su figura se dejaba ver entre el humo de su cigarro en Operación Crossbow (Michael Anderson, 1965) ordenando la destrucción de las bases de las V2 alemanas, mientras que en la canónica La batalla de Inglaterra (Guy Hamilton, 1969), aparecía solo entre sombras. Por entonces se estrenaba en televisión una serie sobre sus orígenes familiares Los primeros Churchill

3. Rodada para conmemorar los 25 años del ascenso al trono de Jorge V. El actor encargado fue C.M. Hallard. 
(David Giles, 1969), centrada en la figura de su más ilustre antepasado, el duque de Marlborough.

\section{Del joven Winston al «líder perdido»}

El mismo año 1895 en que nacía el cine, Churchill se estrenaba como escritor mandando sus primeras crónicas de la guerra de Cuba al londinense Daily Graphic. Desde entonces quedó claro que el principal tema al que dedicaría su pluma sería su propia persona. Cuando se publicó su libro sobre la Gran Guerra, sus adversarios no dudaron en comentar mordazmente que «había escrito una obra sobre él mismo que ha titulado La crisis mundial» (Pelaz, 2012: 146). En efecto, durante toda su vida Churchill tuvo un profundo sentido de la trascendencia histórica de sus propios actos, y se esforzó en dejar constancia de ellos. La mayor parte de su ingente obra escrita, por la que acabaría mereciendo el Premio Nobel de Literatura, fue de carácter histórico y marcadamente autobiográfico (Lukacs, 2002: 101-128). No deja por tanto de ser coherente que la primera película sobre su vida estuviera basada en My early life, publicado en 1930, en el que Churchill definía sus tempranos años como «una larga película en la que yo era uno de los actores» (Churchill, 2010: 52). En 1941 vendió los derechos a la Warner por 7.500 libras, pero la película no se hizo. Tras arduas negociaciones consiguió recuperarlos y en 1956 entabló conversaciones con la MGM, la cual tras un primer acercamiento se desentendió del asunto. Finalmente, en 1961 terminó vendiéndoselos por 100.000 libras a Carl Foreman de la Columbia (Gilbert, 1988: 1204-1207)4.

En 1972 se estrenaba El Joven Winston, el primer y durante mucho tiempo único largometraje que se ocupaba monográficamente de una parte de la vida de Churchill. Se trató de la segunda película dirigida por Richard Attenborough, que se había estrenado apenas unos años antes con ¡Oh que guerra tan bonita! (1969), un musical paródico sobre el comienzo de la Primera Guerra Mundial. Con guion del propio Foreman (un conocido blacklisted), el resultado no fue un biopic al uso, y desde luego muy diferente de lo que hubiera sido de rodarse en 1941.

El punto de partida es de una indudable admiración por el personaje, convincentemente interpretado por Simon Ward, pero incluye algunos elementos ambiguos que no están en la obra autobiográfica original, como la relación freudiana de Winston y su madre (Wenden: 228) y, sobre todo, una

\footnotetext{
4. Los derechos de otras de sus obras como Marlborough: su vida y su tiempo (1933) y la Historia de los pueblos de habla inglesa (1956), fueron adquiridos por Alexander Korda, pero no llegaron a filmarse.
} 
mirada muy de comienzos de los años setenta sobre las glorias imperiales ya periclitadas. La película muestra su difícil infancia en plena época victoriana, y luego se convierte en una auténtica cinta de aventuras narrando sus andanzas en la India, Sudán y la guerra de los bóer (aunque no su breve periplo cubano). Lo más interesante del film es que, bajo el ropaje de una superproducción, no oculta las críticas ni los aspectos más polémicos utilizando un recurso cinematográfico ciertamente poco habitual: un anónimo interrogador fuera de pantalla que somete a Lord Randolph, Lady Churchill y al propio Winston a una serie de cuestiones incómodas (entre ellas la enfermedad inconfesable del padre, la frivolidad de la madre o la ambición desmedida del hijo) durante varios minutos ${ }^{5}$. En definitiva, retrata a un joven pretencioso, lleno de afán de superación, deseoso de ganar la aceptación de su padre (perfil en el que todos los estudiosos coinciden) cuya trayectoria culmina con su primer discurso en la Cámara de los Comunes en 1901 ante la orgullosa mirada de su madre ${ }^{6}$. Todo ello en el contexto de una Inglaterra victoriana, satisfecha de sí misma, en el culmen de su esplendor, pero vista desde 1972 como un mundo felizmente caduco.

Dos años después se volvía sobre los primeros años de Churchill con Jennie: Lady Randolph Churchill (James Cellan Jones, 1974), una serie sobre la madre de Winston en la que este aparecía de forma secundaria en la trama. Si sus años más tempranos despertaron interés, no puede decirse lo mismo de sus primeras décadas en política. La fase más ignorada por el mundo audiovisual ha sido la comprendida entre 1901 y 1929. Se trata, no obstante, de unos años de trascendencia indudable en los que Churchill forjó su personalidad como político, y ocupó diversas carteras ministeriales hasta alcanzar la de Hacienda, habitualmente considerada el peldaño inmediatamente anterior al cargo de primer ministro ${ }^{7}$. Pero fue también la época en la que afrontó algunos de los momentos más polémicos de su vida política. En 1906 protagonizó el sonado cambio desde el partido conservador al liberal, en 1910 envió al ejército contra los mineros galeses, en 1915 tuvo que dimitir como consecuencia del fracaso del desembarco de Gallípoli, en 1924 volvía a la disciplina de los tories, en 1925

5. En la versión doblada al español las entrevistas al padre y a la madre fueron eliminadas. Entre otros cortes también desapareció la escena en la que se sugiere que el destino de Churchill en Sudán fue debido a la relación de Jennie con un oficial del Estado Mayor de Kitchener.

6. En España tuvo 516.152 espectadores en sala. https://sede.mcu.gob.es/CatalogoICAA/ Peliculas/Detalle? Pelicula $=139850$

7. Ministro de Comercio (1908-1910), del Interior (1910-1911), Primer Lord del Almirantazgo (1911-1915), ministro de Armamento (1917-1919), de la Guerra (19191921), de Colonias (1921-1922) y de Hacienda (1924-1929). 
restableció el patrón oro, lo que ha sido generalmente considerado un error mayúsculo, y al año siguiente lideró con mano de hierro la acción del gobierno contra una huelga general, que en buena medida su política económica había provocado. Por no hablar de su encendida defensa del Imperio, de su intento de hacer la guerra a los bolcheviques, etc. Charmley (2014) habla del «líder perdido» para definir estos años, al final de los cuales su carrera parecía definitivamente acabada.

Su actuación en la época previa a la Gran Guerra se rastrea colateralmente en la serie The life and Times of David Lloyd George, (John Hefin, 1981) ${ }^{8}$, o en Titanic: sangre y acero (Ciaran Donnelly, 2012), en la que se puede ver su papel en la crisis de Irlanda. Su relación con el sufragismo aparece en Las Aventuras del joven Indiana Jones (George Lucas, 1992), o en Sufragistas (Sarah Gavron, 2015). La mini serie 37 días (Justin Hardy, 2014) nos acerca a su labor como Primer Lord del Almirantazgo en las decisivas jornadas que siguieron al atentado de Sarajevo. Su actividad durante la Primera Guerra Mundial aparece en la miniserie australiana Deadline Gallipoli (Michael Rymer, 2015) producida con ocasión del centenario de la batalla y bastante crítica en general con la actuación inglesa. En Peaky Blinders (Stephen Knight, 2013-2019) se le ve fugazmente en su condición de ministro de la Guerra que coordina la investigación sobre un robo de armas. La reina del desierto (Werner Herzog, 2015) le muestra como ministro de Colonias en relación con el problema del Medio Oriente tras la liquidación del Imperio otomano. En la serie Kurtulus (Ziya Óztan, 1994) Simon Ward retomaba su icónico papel en un relato sobre la guerra greco-turca posterior al tratado de Sèvres. The Treaty (Jonathan Lewis, 1991) resalta su intervención en la partición de Irlanda de 1921. En su condición de ministro de Hacienda durante la huelga general de 1926 aparecía en Days of Hope, una serie de 1975 dirigida por un joven Ken Loach.

\section{El profeta en el desierto}

Entre 1929 y 1939 Winston Churchill no ocupó ningún cargo en el gobierno aunque continuó manteniendo su condición de diputado. A partir del ascenso de Hitler al poder en 1933 sus intervenciones alertando del peligro alemán empezaron a tener creciente eco. Durante esta época su papel en la llamada «crisis de la abdicación» de 1936 le ha hecho merecedor de atención televisiva en productos cercanos al melodrama rosa. Así tenemos Eduardo y la Sra Simpson (Waris Hussein, 1978), The woman he loved (Charles Jarrott, 1988) y las más recientes Bertie and Elizabeth (Giles Foster, 2002) o Wallis \& Edward

8. El asesor histórico fue AJP. Taylor 
(David Moore, 2005) que, en líneas generales tienden a minimizar su actitud favorable a Eduardo VIII. Estas producciones en cierto sentido no hicieron sino preparar el terreno para que la pantalla grande se ocupara del asunto en El discurso del rey (Tom Hooper, 2010), cinta en la que se combina la abdicación con la creciente amenaza nazi. En esta película el papel de Churchill está claramente distorsionado, ya que sabemos que en realidad se alineó con Eduardo VIII en la defensa de su derecho inalienable a seguir siendo rey, a pesar de las inclinaciones abiertamente pronazis del monarca, y que eso le costó un duro reproche por parte de los Comunes. Un Churchill poco histórico, pero muy cinematográfico: en este caso, el leal consejero que apoya a su nuevo rey Jorge VI porque intuye el estallido de la guerra.

De esta manera llegamos al momento fundacional del mito churchilliano. El papel de Winston Churchill como profeta que clama en el desierto avisando del peligro nazi es la clave para entender su regreso al poder en 1939, como primer lord del Almirantazgo y su ascenso a la jefatura del Gobierno al año siguiente, y por ello ha sido abordado con extensión, sobre todo por la televisión, ya desde hace tiempo. En 1974 el telefilm británico-norteamericano The Gathering Storm (Andrew Osborne y Herbert Wise) ${ }^{9}$ narraba la trayectoria de Churchill, encarnado por Richard Burton, desde la ocupación de Renania en 1936 hasta su discurso del 13 de mayo de 1940 ofreciendo a la nación «sangre, sudor, fatiga y lágrimas». Producido en la estela de El Joven Winston, era la primera vez que un actor encarnaba al personaje para la televisión (Burton ya le había puesto su voz para un documental), y combinaba los momentos de gran intensidad política con escenas de la vida doméstica, en las que destaca el protagonismo de su esposa, que contribuyen a humanizar al gran hombre, inaugurando una línea que habría de tener gran continuación en el futuro.

A comienzos de los ochenta la serie británica, Winston Churchill: The Wilderness Years 1929-1939 (Ferdinand Fairfax, 1981), con la asesoría histórica del biógrafo oficial Martin Gilbert, ofrecía una exhaustiva mirada a esa década en ocho episodios. También abordaba aspectos de la vida privada de Churchill (interpretado por Robert Hardy) como sus problemas económicos, el ámbito familiar, o su tendencia a la depresión. No ocultaba su oposición a la autonomía para la India o su postura en defensa del rey Eduardo VIII, circunstancias ambas que estuvieron a punto de costarle su credibilidad. En lo esencial, no obstante, Churchill no erraba y así en los dos últimos capítulos, dedicados al periodo 1937-1939, se puede ver que sus advertencias estaban fundadas lo cual le lleva a ocupar de nuevo el cargo de primer lord del Almirantazgo.

9. En Reino Unido la BBC lo emitió con el título: Walk on destiny. 
Pero quizá la interpretación más sugerente sobre estos años, sea la del telefilm de HBO Amenaza de tormenta (Richard Loncraine, 2002). Albert Finney nos presenta un Churchill más humano que en otras ocasiones (la primera escena, desnudo orinando, es toda una declaración de intenciones). Un Churchill falible (su empecinamiento en la cuestión de la India), egoísta (la vida de todos los que le rodean debía girar en torno a él), inseguro (piensa que su mujer se ha enamorado de otro y le va a abandonar) y ambicioso (sabe que esta es su última oportunidad de volver al poder). Se subraya la crisis familiar que experimentaron los Churchill en esta época combinándola con su soledad política. Se retrata a su hijo Randolph como bebedor y pendenciero, a Sarah empeñada en su carrera de actriz y en una relación sentimental que Churchill no acepta, y a su esposa, la fiel Clemmie (Vanessa Redgrave), que se ausenta durante meses del hogar familiar y probablemente flirtee con otro hombre. Amenaza de tormenta opta, además, por introducir un elemento ajeno a la vida de los Churchill que permite al espectador involucrarse más en la trama. Se trata de la trayectoria de Ralph Wigram, un alto funcionario del Foreign Office que pasaba información a Churchill sobre el rearme alemán y que murió en oscuras circunstancias. Este drama particular ayuda a mostrar de forma eficaz que la preocupación por los alemanes no era solo cosa de alguien que pretendía utilizar la cuestión como trampolín hacia el poder, sino que Churchill actuó como portavoz de una causa justa que tenía muchos más adeptos dentro del propio establishment. Desde el punto de vista televisivo, el telefilm se alejaba mucho de sus teatrales y un tanto acartonados predecesores.

\section{Realidad y ficción en el instante más oscuro}

Si los años treinta fueron los de Casandra anunciando grandes calamidades, fue su actuación en mayo y junio de 1940 la que consagró el papel de Churchill en la Historia. De ello se ocupa de forma monográfica El instante más oscuro (Joe Wright, 2018) ${ }^{10}$, que contó con la asesoría de John Lukacs (2001; 2008), el trabajo del guionista McCarten (2017) y la interpretación de Gary Oldman, que ganaría un Oscar por ella. Producida en medio de la tormenta política del Brexit, la cinta va más allá que el propio Winston Churchill a la hora de subrayar su mérito en aquella difícil coyuntura. En su historia de la Segunda Guerra Mundial, Churchill mostraba la práctica unanimidad del gobierno a

10. Su título original es Darkest hour, que juega con la expresión Finest hour con la que Churchill definió la actuación británica durante la batalla de Inglaterra. Sobre este momento histórico existe una obra de teatro de 2011, Tres días de mayo, de Ben Brown. En España el film tuvo 241.152 espectadores en sala. https://sede.mcu.gob.es/ CatalogoICAA/Peliculas/Detalle?Pelicula=143017 
la hora de negarse al pacto con Hitler, pero cuando hace pocos años se desclasificaron las actas del gabinete, Lukacs pudo averiguar que las disensiones habían sido muy profundas y que la posibilidad de negociar con los nazis estuvo seriamente encima de la mesa. Mientras que Churchill prefirió en su obra alimentar el mito de la resistencia colectiva, la película opta por ensalzar el mito del héroe individual.

El trabajo de Wright permite plantear algunas consideraciones sobre la relación entre los hechos históricos y las licencias artísticas. La primera tiene que ver con las circunstancias del nombramiento de Churchill como primer ministro. La película arranca el 9 de mayo de 1940 con el debate en los Comunes en el que la oposición pide la dimisión de Chamberlain. Ostensiblemente un movimiento de cámara muestra que el escaño de Churchill está tan solo ocupado por su sombrero Homburg, dando a entender que está eludiendo sus responsabilidades y postulándose como sucesor del primer ministro, «evitando que sus huellas aparezcan en el arma del crimen». Lo cierto es que Churchill estuvo presente en ese debate que trataba sobre la desafortunada campaña noruega (como puede verse en The gathering storm), ya que al ser primer lord del Almirantazgo era en buena medida responsable del desastre sufrido por la flota, y además defendió, no solo su propia gestión, sino también la del primer ministro. Por otra parte, la idea de que Churchill aguardara la comunicación de su nombramiento en su mansión de Chartwell (a 40 kilómetros de Londres) no se ajusta tampoco a la verdad. De hecho la mañana siguiente al voto de censura tuvo lugar una decisiva reunión en Downing Street (hurtada incomprensiblemente por el film) entre Chamberlain, Halifax y Churchill en la que se toma la decisión de proponerle al rey como relevo del primero (y no en una misteriosa cena entre humo de cigarros y sin Winston presente).

La segunda reflexión está relacionada con la inefable escena del metro. En la película, antes de tomar la histórica decisión de continuar la guerra, Churchill se mezcla con la gente común (una selección de individuos que hace las delicias de la corrección política) para preguntarles qué camino tomar. Podría decirse que metafóricamente desciende de la torre de marfil del poder hasta el subsuelo social ${ }^{11}$. Unánimemente la opinión de los pasajeros es que se debe luchar y derrotar a Hitler, pero Churchill no necesitaba preguntarle a la gente porque, como nos cuenta Lukacs, conocía con bastante exactitud el estado de la opinión pública gracias a unas encuestas diarias encargadas por el gobierno. Según su esposa, Churchill solo bajó al metro de Londres una vez en su vida... y se perdió.

11. Uno de los carteles promocionales rezaba: «A man with the heart of a nation». 
Finalmente, la película sitúa el histórico discurso en el que manifiesta su voluntad de luchar en las playas, en los montes y no rendirse jamás, el día 28 de mayo de 1940 (así se ve sobreimpresionado en pantalla), inmediatamente después de su arenga (histórica y bastante fiel) a los miembros del gabinete. En realidad ese discurso se pronunció el 4 de junio, es decir siete días después. La cuestión no tendría más importancia si no fuera porque el día 28 de mayo Churchill todavía no sabía que la Operación Dinamo había sido un éxito y que más de 330.000 soldados aliados habían sido rescatados de Francia. Solo cuando llegan esas noticias anuncia, ya con las tropas en casa, como se ve en Dunkerque (Christopher Nolan, 2018), su decisión de combatir hasta el final. Hacerlo antes hubiera sido una temeridad, incluso para el propio Churchill.

Lo paradójico del caso es que las tres inexactitudes citadas lo que pretenden es subrayar aspectos esencialmente verdaderos de la trayectoria del personaje: que Churchill no era muy bien valorado por sus colegas antes de mayo de 1940, que contaba con el respaldo de buena parte de la sociedad en su decisión de combatir, y que su arenga del 4 de junio (aunque situada el 28 de mayo) fue vital para elevar la moral de los británicos. Es lo que Rosenstone define como «la invención de una verdad», es decir, avalar con situaciones ficticias, hechos verdaderos (1997: 57-61). Las tres escenas además desempeñan su papel en la estructura dramática de la película. La primera presenta al personaje, la segunda permite alcanzar el clímax narrativo y la tercera actúa a modo de conclusión o desenlace. Queda deliberadamente fuera de este relato (y por tanto, del mito) que la decisión de Churchill en última instancia aceleraría el declive del Imperio británico, precisamente lo que Halifax (el villano de la función) y Chamberlain trataban de evitar.

\section{En medio de la tormenta}

Siete años después de Amenaza de tormenta, la HBO produciría En la tormenta (Thadeus O'Sullivan, 2009), con un formato similar (telefilm de 90 minutos) para retomar la acción justo en el momento en el que había concluido la anterior y centrarse en la actuación de Churchill a lo largo de la Segunda Guerra Mundial. Sorprendentemente hasta entonces estos años no habían sido llevado a la pantalla de manera monográfica. Interpretado ahora por Brendan Gleeson, se nos ofrece una visión más convencional del personaje, pero no por ello con menor interés. Gleeson compone un Churchill extrañamente apesadumbrado, que es consciente de que su triunfo en la guerra vendrá acompañado por dolorosas consecuencias en la paz. Del mismo modo que profetizó la amenaza nazi, ahora presiente que los soviéticos se revelarán tan malos o peores que Hitler y que, por si fuera poco, los laboristas le arrebatarán el poder tan preciado. 
Como en Amenaza de tormenta, también aquí es muy importante la presencia de su esposa que, de nuevo, contribuye a humanizar al personaje y a controlar sus arrebatos de mal humor. El punto culminante de la trama es, por supuesto, el año 1940, con especial atención a los debates del gabinete de finales de mayo, pendientes del transcurso de los acontecimientos en Dunkerque. El resto de la guerra es despachado con cierta rutina. Llaman la atención algunas ausencias, cómo su relación con Stalin (la invasión de la URSS ni siquiera aparece), o la conferencia de Potsdam. Y destaca también cierto interés en justificar el bombardeo de Dresde. El balance final del conflicto que hace Churchill es demoledor: «es el fin de nuestro mundo: el imperio, el respeto por el viejo orden», pesimismo que intenta ser compensado con la escena final del aplauso en el teatro, último homenaje del pueblo agradecido a su héroe salvador. A diferencia de El instante más oscuro, la película se acerca a la tesis historiográfica según la cual Churchill terminó provocando justamente lo que había querido evitar (Charmley, 2014).

La actuación de Churchill durante la guerra ha sido parcialmente llevada a la pantalla en numerosas producciones (ver Cuadro 1). A veces a través del relato de hechos concretos como la conferencia de Yalta, la acción contra la flota francesa en Mers El-Kebir, el fallido desembarco de Dieppe, el papel de Australia en la guerra, la trama del espía Cicerón o las acciones contra las bombas volantes alemanas. En otras ocasiones mediante su relación con otros personajes muy frecuentados (y también mitificados) por el cine y la televisión como Eisenhower, Roosevelt o el general de Gaulle. Los rusos le hacen aparecer en su monumental La Batalla de Berlín (Yury Ozerov, 1971), se le utiliza como atrezzo histórico dentro de melodramas como Vientos de guerra (Dan Curtis, 1983) y su continuación Recuerdos de guerra (Dan Curtis, 1989), y a veces incluso se ha dejado volar la imaginación planteando su hipotético secuestro por los nazis en Ha llegado el águila (John Sturges 1970) o Casablanca express (Sergio Martino, 1988).

Si 1940 fue el momento en el que Churchill «no perdió la guerra» (Robbins, 2003:168), 1944 fue el año en el que, por fin, estuvo en disposición de ganarla. Por eso sorprende un tanto el contrapunto al exultante Churchill de Gary Oldman que compone el sombrío Brian Cox en Churchill (Jonathan Teplitzky, $2017)^{12}$. La tesis de esta cinta es que Churchill habría intentado evitar el desembarco de Normandía para impedir así un baño de sangre. El interés de la película reside en ver cómo el gran hombre de 1940 había ido progresivamente

12. Los espectadores en sala en España fueron 98.047. https://sede.mcu.gob.es/CatalogoICAA/ Peliculas/Detalle?Pelicula $=82517$ 
perdiendo el control de los acontecimientos, sobre todo desde la entrada de los americanos en la guerra. Sus objeciones al desembarco en Normandía son conocidas por los historiadores, y de hecho intentó retrasar (y lo consiguió) la operación lo más posible hasta que los rusos en el frente del Este hubieran desangrado a la Werhmacht. Pero no parece muy verosímil ese dramático arranque de indecisión a pocas fechas del día D. Según Roberts (2018) se trata de la peor película jamás hecha sobre Churchill y señala al menos 120 errores históricos en ella.

\section{El último rugido}

Tras el final de la guerra, lejos de retirarse, Churchill continuó en la política activa como líder de la oposición entre 1945 y 1951. Así puede vérsele en relación a la independencia de la India en la pantalla pequeña en Lord Mountbatten: The last viceroy (Tom Clegg, 1986) y en la grande en El último virrey de la India (Gurinder Chadha, 2017), en la que se le atribuye un maquiavélico plan para la partición del subcontinente. En la serie Cerca de tu enemigo (Stephen Poliatoff, 2016) aparece en los albores de la Guerra Fría.

El interés por los últimos años de la carrera política de Churchill es muy reciente. En la primera temporada de la serie The Crown (Peter Morgan, 2016), se nos proporciona una sugerente visión sobre su última etapa en el poder, entre 1951 y 1955. El contraste entre Isabel II, la joven e inexperta soberana, y su envejecido primer ministro sirve a efectos dramáticos para presentar estos años como el último servicio que el gran hombre presta a su país, asesorando lealmente a su joven reina. En el capítulo cuarto un Churchill aparentemente acabado y acosado por todos (la reina, su propio gobierno, la oposición), todavía tiene suficientes reflejos y se termina presentando como el líder que la nación necesita en tiempos difíciles. En el séptimo, sin embargo, es Isabel II la que da una lección constitucional al primer ministro, que en 1953 le oculta (como a casi todo el gabinete) que había sufrido una embolia que le dejó incapacitado y sin habla durante varios meses. Finalmente, el noveno está centrado enteramente en la retirada de Churchill de la política. Con ocasión de su 80 cumpleaños, los Comunes encargan al pintor Graham Sutherland que le haga un retrato para ofrecérselo como regalo, una forma sutil de indicarle, tal vez, la puerta de salida. Churchill insiste en ser retratado en su mejor hora, mientras que el pintor desea inmortalizarle tal y como le ve, en plena decadencia. A través de las conversaciones entre ambos Churchill comprende por fin que debe renunciar al poder, lo cual hace en una emotiva última audiencia con la 
reina ${ }^{13}$. En la escena final puede verse a su esposa Clementine quemando el cuadro, salvando así, metafóricamente, la imagen del héroe.

El episodio de la embolia sufrida en 1953 es abordado de manera monográfica en El secreto de Churchill (Charles Sturridge, 2016). El telefilm se centra por un lado en la fortaleza de voluntad de Churchill que, contra la opinión de todo el mundo incluido su médico, consigue reponerse de un ataque que le coloca al borde de la muerte. Pero, por otro, también subraya la irresponsabilidad de un anciano aferrado al poder, que no duda en colocar al país ante una grave crisis constitucional. También es interesante el demoledor panorama que traza de la familia Churchill, anunciando ya el trágico final de algunos de sus hijos, la prematura muerte por alcoholismo de Randolph o el suicidio de Diana.

El retrato de Churchill tras su definitiva salida del poder en 1955 es poco frecuente. Se puede mencionar Suez, 1956 (Michael Darlow, 1979) sobre la crisis política que produjo la nacionalización del canal por parte de Egipto. Y también sus apariciones en biopics sobre Onassis, a caballo entre la historia y la crónica rosa, casos de Onassis: el hombre más rico del mundo (Waris Hussein, 1988) y Callas y Onassis (Giorgio Capitani, 2005). En estas series Churchill aparece como mera comparsa, si bien siempre tratado con el debido respeto.

\section{Otras formas de ver a Churchill}

Algunas películas o series en las que aparece Churchill desde hace unos años apuntan que la realidad se ha visto superada por la ficción. En 2004 el largometraje Churchill: The Hollywood years (Peter Richardson) parodiaba la historia de la batalla de Inglaterra presentando a Winston como un héroe de acción de película de adolescentes. Hitler llega a Londres para casarse con la princesa Elisabeth y consumar la unión entre el Imperio británico y el Tercer Reich. Pero esta maniobra es impedida por Winston Churchill, un improbable Christian Slater, que a modo de Rambo, impide la boda. En una línea parecida, aunque más absurda si cabe, Churchill hace una aparición en FDR: American Badass! (Garrett Brawith, 2012) cuyo argumento se centra en el combate del presidente Franklin Roosevelt contra los hombres lobo.

Jackboots on Whitehall (Edward y Rory McHenry, 2010), es una cinta de animación realizada con la técnica de stop motion, en la que los nazis excavan un túnel por debajo del Canal y llegan al centro de Londres $^{14}$. Su objetivo es capturar a Churchill que de esta manera ve interrumpidos sus planes de

13. El actor que encarna al pintor es Stephan Dillane, Lord Halifax en El Instante más oscuro.

14. Tan solo fue vista en salas por 28.269 espectadores en España. https://sede.mcu.gob.es/ CatalogoICAA/Peliculas/Detalle?Pelicula=198009 
jubilación. Ayudado por unos campesinos, un batallón de sikhs, un francés y un yanqui, Churchill huye hacia Escocia. En su apoyo acudirán las tribus de highlanders lideradas por Braveheart y juntos derrotan a los nazis en una sangrienta batalla final. La historia se confunde con el mito, la realidad con la ficción, los actores con muñecos animados. El resultado es un Churchill que trasciende la historia. Se convierte en un personaje de leyenda.

Podríamos continuar con un par de ejemplos más. En Malditos bastardos (Quentin Tarantino, 2009), Churchill es un ilustre atrezzo, encarnado por un venerable Rod Taylor. En Doctor Who (2010) aparece en varias ocasiones como amigo del protagonista. En una de ellas el Doctor debe convencer a Winston de que no utilice un arma secreta de origen alienígena durante la batalla de Inglaterra para derrotar a la Luftwaffe.

Recientemente Churchill ha dado el salto a los videojuegos. En 2014 se añadieron tres DLC a Sniper Elite III titulados «Salvar a Churchill» en los que el protagonista debía evitar que se cometiera un atentado contra Churchill aprovechando su presencia en la Conferencia de Casablanca ${ }^{15}$. En 2016 Donald Rumsfeld, que fuera secretario de Defensa con Bush, lanzó para el sistema iOS el juego Churchill Solitaire, una versión del juego del solitario a la que el primer ministro era muy aficionado. En la aplicación aparecen videos y audios con pasajes de la vida del personaje ${ }^{16}$. En 2015 se puso a la venta Churchill Big Three Struggle for peace (Mark Herman, GMT) un juego de mesa ambientado en las conferencias interaliadas durante la guerra.

\section{Conclusiones. Érase una vez Churchill}

Dice Rosenstone que «a diferencia de las biografías escritas, los biopics rara vez intentan abarcar toda una vida» (2014: 176). Esta máxima se cumple también en el caso de Churchill pero con una interesante salvedad, y es que el cine y la televisión han terminado por construir una especie de «relato de relatos» que se ajusta además a los cánones dramáticos del héroe clásico siguiendo una estructura en tres actos (Sánchez Escalonilla, 2002: 36-37). El primero sería la forja del héroe, sus pasos iniciales en los que ya despuntan sus cualidades de liderazgo y, sobre todo su valor, probado incluso en la batalla. Esta etapa la cubre El joven Winston, aunque el mensaje final quedara matizado por el espíritu crítico posterior al 68 que le infundieron director, guionista y productor. En el segundo acto el héroe avisa de grandes calamidades sufriendo el

15. https://www.micromania.es/sniper-elite-3-salvar-a-churchill/.

16. http://www.fsgamer.com/el-ex-secretario-de-defensa-donald-rumsfeld-publica-el-videojuego-churchill-solitaire.html 
rechazo de todos, hasta que se comprueba que tiene razón y que no se puede contemporizar con los malvados sino vencerlos. Es sin duda, la etapa que más atención ha recibido y en la que se incluyen dos largometrajes, tres telefilmes y una serie de varios capítulos, entre los cuales destaca sobre todo El instante más oscuro, que pone el foco sobre los cruciales días de mayo de 1940. Finalmente el tercer acto se cierra con la retirada del héroe, no sin antes realizar un servicio postrero, ofreciendo sus sabios consejos a la joven reina. Los últimos años del gran hombre, presentes en The Crown o El secreto de Churchill, nos muestran su lucha contra la decadencia y en ultimo término sugieren que con él termina una etapa de gigantes de la política, irrepetibles ya en el presente.

Pero tan interesante como comprobar en qué momentos de la vida de Churchill se han centrado las producciones audiovisuales, es hacerlo con aquellos otros deliberadamente ignorados. Así los treinta primeros años de su carrera política no han despertado demasiado interés, fuera de apariciones esporádicas en películas o series dedicadas a otros asuntos o personajes. Es precisamente la etapa en la que se condensan los aspectos más controvertidos en la biografía de Churchill, porque, como apunta Bédarida (2002: 23), también existe «una leyenda negra, reduciendo al hombre de Estado, en ocasiones, al papel de cínico secuaz de la realpolitik y de politicastro egoísta movido por una fuerza de voluntad destructora y asesina, y en otras al de aprendiz de brujo de un nacionalismo cerrado, anacrónico y obsoleto». El cine y la televisión han preferido no explorar demasiado esta faceta del personaje quizá porque se aleja demasiado de la imagen canónica ya preconcebida.

Conviene constatar cómo las principales producciones cinematográficas sobre Churchill nos hablan de la propia evolución de la sociedad británica (Frago; Sierra, 2020). En los 70 El joven Winston se estrenaba con el imperio en liquidación, en plena decadencia económica, y en medio del debate sobre la entrada en el Mercado Común, una serie de circunstancias que marcaban el punto más bajo en el ánimo británico desde la guerra, traducidas en una perceptible crisis de identidad que culminaría con la llegada al poder de Margaret Thatcher. Medio siglo después, películas como Dunkerque, Churchill o El instante más oscuro nacen en medio de una nueva sacudida identitaria, la provocada por el Brexit, alimentada en buena medida por la vieja nostalgia imperial y promovida entre otros por un primer ministro que además es biógrafo de Churchill, (Johnson, 2015). Esto ha llevado al crítico de cine Carlos Boyero a afirmar que Churchill «no es una mera figura histórica, ni un simple personaje cinematográfico en el interior de su propio biopic, sino un icono cuya invocación/activación necesita ser debidamente ritualizada» por los británicos necesitados en la actualidad de «forjar una nueva mitología de la autoestima 
nacional» (Boyero, 2018). La ya citada escena del metro en la obra de Wright parece avalar el intento por situar a Churchill por encima de las divisiones sociales, de edad, género y raza ${ }^{17}$.

Rosenstone nos recuerda que en las películas que llama «tradicionales», la historia se explica muchas veces a través de un conflicto moral ante el que los protagonistas deben hacer que el bien triunfe sobre el mal (1997: 50-53). Esta estrategia encuentra su máxima expresión en el biopic que, según el crítico de cine Ronald Bergan, «es una ficción que no se atreve a confesar que lo es... (toma) las vidas reales de las personas y las convierte en lugares del mito» (Rosenstone, 2014: 161). En el caso que nos ocupa, parece evidente que la enorme fuerza que conserva el mito de Churchill reside en que se enfrentó y venció a la encarnación misma del mal por antonomasia en el siglo XX: el nazismo. Se trataba de una decisión moral ante la cual cabían pocas dudas y que eclipsa las consecuencias negativas que pudiera haber tenido (el debilitamiento del Imperio), además de poner sordina a otras facetas de su biografía menos edificantes (Lukacs, 2002: 101-128). Este planteamiento condiciona también la consideración que merece el apaciguamiento de los años treinta, y así Baldwin, Chamberlain y, desde luego, Halifax, no reciben un tratamiento muy positivo en pantalla, proyectando el maniqueísmo no solo en contra de Hitler, sino respecto a los que pretendieron pactar con él, los guilty men a los que alude Tim Bouverie (2020). Esta idea subyace en la mayoría de los biógrafos del personaje:

«Nos mostró a todos sus virtudes y sus defectos de un modo teatral, como un gran actor representando su papel ante la posteridad, un papel innato. Y si bien es verdad que Churchill trató de dar siempre una imagen heroica, no lo es menos que nadie puede con mayor derecho ser considerado como un verdadero héroe» (Brendon, 1994: 252)

En términos generales, pues, la historiografía y la historiofotía de la que hablaba Hayden White (2010: 217-227) coinciden, pero en el caso de Churchill habría que tener en cuenta una tercera dimensión, la de la cultura popular. Como señala De Groot, debemos dejar de mirar a las novelas, las películas, las obras de teatro, los juegos o las series de televisión, como pobres versiones de la historia o como parásitos que se apropian del conocimiento histórico, para valorarlas como fórmulas nuevas de adquirir conciencia del pasado, de participar en él, de narrarlo o comprenderlo (2016b: 6) En esa línea irían productos que desbordan

17. No obstante, no parecen necesarias estrategias un tanto pueriles, como la casi obligada presencia de la joven secretaria que logra que el líder se humanice (El instante más oscuro, Churchill, The Crown) o, en su defecto, de una no menos agraciada enfermera (El secreto de Churchill). 
el marco de los hechos adentrándose por el territorio de la «historia-ficción», los videojuegos o el merchandising que rodea al personaje. Incluso la vandalización de su estatua londinense en 2020 vendría a mostrar que Churchill ha trascendido su condición de personaje histórico para convertirse en un símbolo, respecto al que hay que pronunciarse a favor o en contra.

En un artículo titulado «Érase una vez Churchill» Umberto Eco (2008) comentaba una encuesta según la cual «un cuarto de los ingleses piensa que Churchill es un personaje de fantasía y lo mismo sucede con Gandhi y Dickens». La conclusión que extraía era que cada vez es más difícil «que un usuario de películas capte la diferencia temporal entre Espartaco y Ricardo Corazón de León. E igualmente, la diferencia entre imaginario y real se aplasta o, en cualquier caso, pierde toda consistencia». Andrew Roberts (2019) argumenta que esa confusión en el caso de Winston Churchill prueba su carácter de mito y refuerza la idea de su grandeza. Churchill llegó a decir que «la Historia me justificará, sobre todo porque la escribiré yo mismo» (Bédarida, 2002: 22). Cada vez más ese papel de juez lo ejercerán también los medios audiovisuales.

\section{Bibliografía}

BÉDARIDA, François (2002). Churchill. Madrid: FCE.

BOYERO, Carlos (11 de enero de 2018). El regreso de papá Brexit. https://elpais. com/cultura/2018/01/11/actualidad/1515675744_659726.html

BRENDON, Piers (1994). Winston Churchill. Barcelona: Planeta de Agostini.

BROWN, Ted; VIDAL, Belén (eds.) (2014). The Biopic in Contemporary Film Culture. New York: Routledge. https://doi.org/10.4324/9780203384572

BOUVERIE, Tim (2020). Apaciguar a Hitler. Hitler, Chamberlain, Churchill y el camino a la guerra. Barcelona: Debate.

BURDIEL, Isabel (coord.) (2014). Los retos de la biografía. Dossier. En Ayer, 93, (1). https://www.marcialpons.es/media/pdf/9788415963158.pdf

CAMARERO, Gloria (ed.) (2011). La biografía filmica: actas del Segundo Congreso Internacional de Historia y Cine (cd-rom). Madrid: T\&B editores. https://earchivo.uc3m.es/handle/10016/11295

COLVILLE, John (2007). A la sombra de Churchill. Diarios de Downing Street 19391955. Barcelona: Galaxia Gutenberg, Círculo de Lectores.

CHARMLEY, John (2014). Churchill. The end of Glory. A Political Biography. London: Faber \& Faber.

CHURCHILL, Winston (1943). Pensamientos y aventuras. Barcelona: Talleres Gráficos Agustín Núñez.

CHURCHILL, Winston (2010). Mi juventud. Autobiografía. Granada: Almed. 
DE PABLO, Santiago (2001). Cine e historia: ¿La gran ilusión o la amenaza fantasma?. En Historia Contemporánea, (I), 22, 9-28. https://addi.ehu.es/bitstream/ handle/10810/37891/15812-57242-1- PB.pdf? sequence=1\&isAllowed=y

DE GROOT, Jerome (2016a). Consuming History. Historians and heritage in contemporary popular culture. London and New York: Routledge (edición de Kindle). https://doi.org/10.4324/9781315640754

DE GROOT, Jerome (2016b). Remaking History. The past in contemporary historical fictions. London and New York: Routledge (edición de Kindle). https://doi. org/10.4324/9781315693392

DOSSE, François (2007). El arte de la biografía. México: Universidad Iberoamericana.

ECO, Humberto (2008). Erase una vez Churchill. https://www.elespectador.com/ opinion/erase-una-vez-churchill-columna-12210.

ERICE, Francisco (2020). En defensa de la razón. Contribución a la crítica del posmodernismo, Madrid: Siglo XXI (edición de Kindle).

FERRO, Marc (1995). Historia contemporánea y cine. Barcelona: Ariel.

FERRO, Marc (2008). El cine, una visión de la Historia. Madrid: Akal.

Finest hour, 179, Winter 2018, Monográfico: Churchill at the movies. https://winstonchurchill.org/publications/finest-hour/finest-hour-179/

FISHMAN, Jack (1964). Mi querida Clementina. La historia de Lady Churchill. Barcelona: Ayma.

FRAGO, Marta, SIERRA, Daniel (2020). El joven Winston y El Instante más oscuro: Winston Churchill como líder político en una Europa cambiante. En Fotocinema, 21, 59-81. https://doi.org/10.24310/Fotocinema.2020.vi21.9999

GILBERT, Martin (1988). Never dispair. Winston S. Churchill 1945-1965. London: Minerva.

GILBERT, Martin (2006). Churchill and America, London: Pocket Books.

GÓMEZ NAVARRO, José Luis (2005). En torno a la biografía histórica. En Historia y política, 13, 7-26. https://recyt.fecyt.es/index.php/Hyp/article/view/44706

HASTINGS, Max (2010). La guerra de Churchill. La historia ignorada de la Segunda Guerra Mundial. Barcelona: Crítica.

HAYWARD, Steven F. (2008). Grandeza. Reagan y Churchill, dos líderes extraordinarios. Madrid: Gota a gota.

HAYWARD, Steven F. (2017). Can Darkest Hour avoid the pitfalls that have payed so many Churchill films?. https://www.weeklystandard.com/steven-f-hayward/ can-darkest- hour-avoid-the-pitfalls-that-have-plagued-so-many-churchill-films

HERNÁNDEZ, Sira (2004). Hacia una definición del documental de divulgación histórica. En Comunicación y sociedad, Vol XVII, 2, 89-123. https://dadun.unav. edu/bitstream/10171/34811/1/89historica.pdf

HUESO, Ángel Luis (2001). La biografía como modelo histórico-cinematográfico. En Historia Contemporánea, 22, 97-115. https://ojs.ehu.eus/index.php/HC/ article/view/15820 
JENKINS, Roy (2002). Churchill. Barcelona: Península.

JOHNSON, Boris (2015). El factor Churchill. Un solo hombre cambió el rumbo de la Historia. Madrid: Alianza Editorial.

LORD MORAN (1967). Winston Churchill (Memorias de su médico). Madrid: Taurus.

LUKACS, John (2001). Cinco días en Londres, mayo de 1940. Churchill solo frente a Hitler. Madrid: Turner.

LUKACS, John (2002). Churchill. Visionary, Statesman, Historian. Yale University Press.

LUKACS, John (2008). Sangre, sudor y lágrimas: Churchill y el discurso que ganó una guerra. Madrid: Turner.

MCCARTEN, Andrew (2017). El instante más oscuro. Winston Churchill en mayo de 1940. Barcelona: Crítica.

MONTERO, Julio (2001). Fotogramas de papel y libros de celuloide: el cine y los historiadores. Algunas consideraciones. En Historia Contemporánea, (I), 22, 29-66. https://addi.ehu.es/handle/10810/37899

NASAW, David (2005). Hearst. Un magnate de la prensa. Barcelona: Tusquets.

PEARSON, John (1993). La dinastía Churchill. Buenos Aires: Javier Vergara.

PELAZ, José-Vidal (2012). Breve historia de Winston Churchill. Madrid: Nowtilus. PILARD, Philippe (1998). El cine británico. Madrid: Acento Editorial.

ROBBINS, Keith (2003). Churchill. Madrid: Biblioteca nueva.

ROBERTS, Andrew (2003). Hitler y Churchill. Los secretos del liderazgo. Madrid: Taurus.

ROBERTS, Andrew (2018). Andrew Robert's guide to Churchill on screen. https:// www.spectator.co.uk/2018/01/andrew-robertss-guide-to-churchill-on-screen/

ROBERTS, Andrew (2019). Churchill. La biografía. Barcelona: Crítica (edición de Kindle).

ROSENSTONE, Robert (1997). El pasado en imágenes. El desafío del cine a nuestra idea de la historia. Barcelona: Ariel.

ROSENSTONE, Robert (2014). La historia en el cine. El cine sobre la historia. Madrid: Rialp.

RUEDA, José Carlos; CORONADO, Carlota; SÁNCHEZ, Raquel (2009) La historia televisada una recapitulación sobre narrativas y estrategias historiográficas. En Comunicación y Sociedad, 12, 177-202. https://eprints.ucm.es/id/eprint/9807/

SÁNCHEZ ESCALONILLA, Antonio (2002). «Relato audiovisual y espectador eterno». En José-Vidal PELAZ; José Carlos RUEDA (eds.) Ver cine. Los públicos cinematográficos en el siglo XX (35-52). Madrid: Rialp.

SAND, Schlomo (2004). El siglo XX en pantalla. Barcelona: Crítica.

SORLIN, Pierre (1980). The Films in History. Restaging the Past. Oxford: Blackwell. SORLIN, Pierre (1996). Cines europeos, sociedades europeas 1939-1990. Barcelona: Paidós. 
WENDEN, David John (1993). Churchill, Radio, and Cinema. En Robert BLAKE; William Roger, LOUIS. Churchill. A Major new assessment of his Life in Peace and War, (215-239). New York: Oxford University Press.

WHITE, Hayden (2010). Ficción histórica, historia ficcional y realidad histórica. Buenos Aires: Prometeo Libros. 